\title{
Mesenchymal stromal cells for the treatment of critical limb ischemia: context and perspective
}

\author{
Hendrik Gremmels, Joost O Fledderus, Martin Teraa and Marianne C Verhaar ${ }^{*}$
}

\begin{abstract}
Cell therapy using mesenchymal stromal cells (MSCs) is a promising new avenue of treatment for critical limb ischemia (CLI). Preclinical studies have suggested that MSCs enhance neovascularization in ischemic limbs. In this commentary, we discuss a recent study by Gupta and colleagues, one of the first human trials using allogeneic MSCs for $\mathrm{CLI}$, in relation to the current state of knowledge regarding cell therapy for CLI.
\end{abstract}

Recently, Gupta and colleagues [1] reported the results of a randomized double-blind placebo-controlled phase I/II study on the efficacy and safety of allogeneic mesenchymal stromal cells (MSCs), administered by intramuscular injection in patients with critical limb ischemia (CLI). Because the number of randomized controlled trials investigating stem cell therapy in peripheral arterial disease (PAD) is limited, this study is a welcome addition. Gupta and colleagues are also one of the first groups to apply MSCs in PAD.

Roughly a dozen clinical trials investigating stem or progenitor cell therapy in patients with CLI have been reported, but many were of limited size and not placebocontrolled [2]. In most studies, the cell therapy product under investigation consisted of autologous bone marrow mononuclear cells (BMCs), which is a heterogeneous mixture of cells obtained by density gradient centrifugation of bone marrow aspirate. Infusion of BMCs has been reported to lead to improvements in ankle-brachial index $(\mathrm{ABI})$ and pain-free walking distance. However, the quality of evidence for efficacy is limited, as most studies lacked a proper placebo or sham group for the invasive bone marrow-harvesting procedure that is required for a study investigating autologous material.

\footnotetext{
* Correspondence: m.c.verhaar@umcutrecht.nl

Department of Nephrology and Hypertension, Hp F03.227, University Medical Center Utrecht, Heidelberglaan 100, 3584 CX, Utrecht, The Netherlands
}

Advances in good manufacturing practice-compliant production of more sophisticated cell products are now opening up the way to a second generation of cell therapy trials. MSCs, which are obtained by expansion of adherent bone marrow cells in ex vivo culture, have the capacity to enhance neovascularization and are a promising candidate for cell therapy in CLI. Owing to their inherent low antigenicity, MSCs may be administered in allogeneic recipients [3]. Although allogeneic administration has been shown to be safe [4], eventual immunization may occur upon differentiation of residual injected cells [5]. Because the pro-angiogenic effects of MSCs occur relatively quickly after administration [6], delayed immunization does not appear to be an obstacle when MSCs are given as a single-time administration. In advanced arterial occlusive disease, as in CLI, it may preferable to give multiple doses, especially considering the relative ease of administration and the lack of an acute indication. It remains to be elucidated whether allogeneic MSCs are sufficiently immunoprivileged to prevent alloimmunization if they are administered repeatedly in a 'vaccination scheme'.

Animal [7] and human [8] studies comparing efficacy of BMCs and MSCs in ischemic limbs suggest that MSCs are superior to BMCs in promoting neovascularization. The study by Gupta and colleagues, though designed primarily to assess safety and feasibility, shows a substantial improvement in ABI. To illustrate the treatment effect in relation to other studies, we have added a meta-analytic scatterplot plot showing $\mathrm{ABI}$ increases after cell therapy observed by Gupta and colleagues and three prior [8-10] placebo-controlled studies that report the same outcome measure (Figure 1).

Gupta and colleagues are to be commended for including a placebo arm in their study, as the invasiveness of cell injections often prevents researchers from including controls in early-phase clinical studies. Unfortunately, it is not entirely clear how blinding in this study was performed for either patients or treating physicians or whether blinding was successfully maintained throughout the study. For instance, the placebo administered by the 


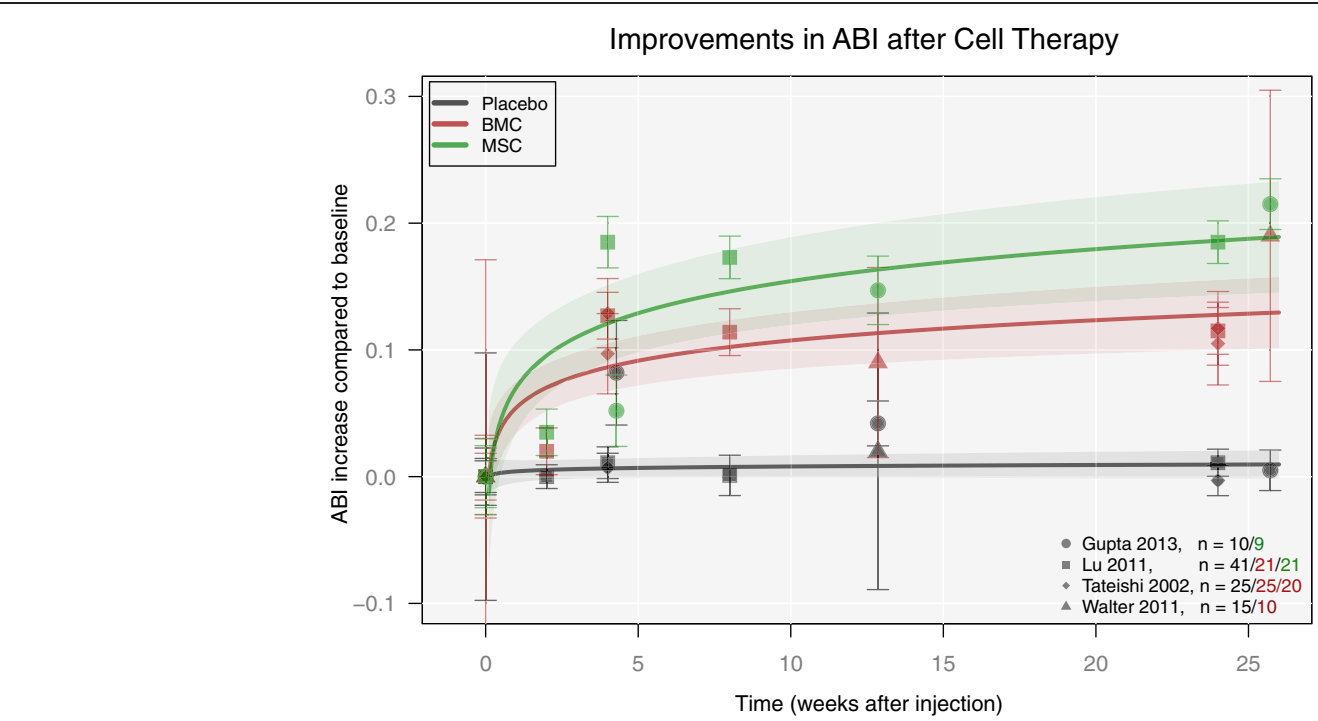

Figure 1 Improvements in ankle-brachial index (ABI) after cell therapy. Meta-analytic scatterplot with meta-regression lines shows improvements in ABI compared with baseline after injection of a cell-therapy product or placebo. The two bone marrow mononuclear cell (BMC) cohorts in the study by Tateishi-Yuyama and colleagues [9] were included separately. Regression lines were fit with a mixed model using REML (restricted maximum likelihood) estimation; bands show 95\% confidence intervals. This figure was prepared with the 'metafor' [11] package in 'R'. MSC, mesenchymal stromal cell.

authors is a balanced crystalloid solution that is likely to be easily distinguished from the serum-containing (and potentially dimethylsulfoxide-containing) cryopreservation medium in which the cell product was suspended. A rigorously blind study design is essential to exclude confounding factors, which may lead to an overestimation of treatment effects [12].

Another consideration in the interpretation of the findings reported by Gupta and colleagues is that the study population consists of both patients with an arteriosclerotic disease etiology and patients with thromboangitis obliterans, but the authors do not report in which proportions. In previous studies, it has been shown that disease etiology is an important determinant of treatment success [13], which makes this omission somewhat unfortunate.

The mechanism of action behind MSC-mediated improvements in perfusion is, at present, still poorly understood. MSC tracing studies in animal models show that MSCs are retained for only a short period of time in injected limbs $[6,14]$ and that incorporation into the vascular bed does not contribute to the observed proangiogenic effects [6]. Rather, MSCs are thought to act through paracrine effects, either directly on the local endothelium [15] or indirectly through the recruitment of angiogenic monocytes [14]. These functions are likely to be unrelated to the multipotent capability of MSCs, and it is unclear whether using whole cells has an added functional benefit (for example, through homing) above their secreted growth factors [16]. There is even considerable discussion whether cell therapy with MSCs deserves the epithet of stem cell therapy at all [17]. Regardless of these considerations, the studies by Gupta and colleagues and others show that further development of MSC therapy is, at the very least, a promising avenue in the treatment of patients with very few other options.

\section{Abbreviations}

ABI: Ankle-brachial index; BMC: Bone marrow mononuclear cell; CLI: Critical limb ischemia; MSC: Mesenchymal stromal cell; PAD: Peripheral arterial disease.

\section{Competing interests}

The authors declare that they have no competing interests.

Published: 18 Nov 2013

\section{References}

1. Gupta PK, Chullikana A, Parakh R, Desai S, Das A, Gottipamula S, Krishnamurthy S, Anthony N, Pherwani A, Majumdar AS: A double blind randomized placebo controlled phase $\mathrm{I} / \mathrm{II}$ study assessing the safety and efficacy of allogeneic bone marrow derived mesenchymal stem cell in critical limb ischemia. J Transl Med 2013, 11:143.

2. Teraa M, Sprengers RW, van der Graaf Y, Peters CEJ, Moll FL, Verhaar MC: Autologous bone marrow-derived cell therapy in patients with critical limb ischemia: a meta-analysis of randomized controlled clinical trials. Ann Surg 2013 [Epub ahead of print].

3. Le Blanc K, Tammik C, Rosendahl K, Zetterberg E, Ringdén O: HLA expression and immunologic properties of differentiated and undifferentiated mesenchymal stem cells. Exp Hematol 2003, 31:890-896.

4. Lalu MM, Mclntyre L, Pugliese C, Fergusson D, Winston BW, Marshall JC, Granton J, Stewart DJ: Safety of Cell Therapy with Mesenchymal Stromal Cells (SafeCell): a systematic review and meta-analysis of clinical trials. PLOS ONE 2012, 7:e47559.

5. Huang X-P, Sun Z, Miyagi Y, McDonald Kinkaid H, Zhang L, Weisel RD, Li RK: Differentiation of allogeneic mesenchymal stem cells induces immunogenicity and limits their long-term benefits for myocardial repair. Circulation 2010, 122:2419-2429.

6. Schwarz TM, Leicht SF, Radic T, Rodriguez-Araboalaza I, Hermann PC, Berger F, Saif J, Böcker W, Ellwart JW, Aicher A, Heeschen C: Vascular incorporation of endothelial colony-forming cells is essential for functional recovery of 
murine ischemic tissue following cell therapy. Arterioscler Thromb Vasc Biol 2012, 32:e13-e21.

7. Iwase T, Nagaya N, Fujii T, Itoh T, Murakami S, Matsumoto T, Kangawa K, Kitamura S: Comparison of angiogenic potency between mesenchymal stem cells and mononuclear cells in a rat model of hindlimb ischemia. Cardiovasc Res 2005, 66:543-551.

8. Lu D, Chen B, Liang Z, Deng W, Jiang Y, Li S, Xu J, Wu Q, Zhang Z, Xie B, Chen S: Comparison of bone marrow mesenchymal stem cells with bone marrowderived mononuclear cells for treatment of diabetic critical limb ischemia and foot ulcer: a double-blind, randomized, controlled trial. Diabetes Res Clin Pract 2011, 92:26-36.

9. Tateishi-Yuyama E, Matsubara H, Murohara T, Ikeda U, Shintani S, Masaki H, Amano K, Kishimoto Y, Yoshimoto K, Akashi H, Shimada K, Iwasaka T, Imaizumi T, Therapeutic Angiogenesis using Cell Transplantation (TACT) Study Investigators: Therapeutic angiogenesis for patients with limb ischaemia by autologous transplantation of bone-marrow cells: a pilot study and a randomised controlled trial. Lancet 2002, 360:427-435.

10. Walter DH, Krankenberg H, Balzer JO, Kalka C, Baumgartner I, Schlüter M, Tonn T, Seeger F, Dimmeler S, Lindhoff-Last E, Zeiher AM, PROVASA Investigators: Intraarterial administration of bone marrow mononuclear cells in patients with critical limb ischemia: a randomized-start, placebo-controlled pilot trial (PROVASA). Circ Cardiovasc Interv 2011, 4:26-37.

11. Viechtbauer $\mathrm{W}$ : Conducting meta-analyses in $\mathrm{R}$ with the metafor package. J Stat Software 2010, 36:1-48

12. Jeong H, Yim HW, Cho Y, Park HJ, Jeong S, Kim H-B, Hong W, Kim H: The effect of rigorous study design in the research of autologous bone marrow-derived mononuclear cell transfer in patients with acute myocardial infarction. Stem Cell Res Ther 2013, 4:82.

13. Idei N, Soga J, Hata T, Fujii Y, Fujimura N, Mikami S, Maruhashi T, Nishioka K, Hidaka T, Kihara Y, Chowdhury M, Noma K, Taguchi A, Chayama K, Sueda T, Higashi Y: Cell therapy for critical limb ischemia: moving forward one step at a time. Circ Cardiovasc Interv 2011, 4:2-5.

14. Ryu JC, Davidson BP, Xie A, Qi Y, Zha D, Belcik JT, Caplan ES, Woda JM, Hedrick CC, Hanna RN, Lehman N, Zhao Y, Ting A, Lindner JR: Molecular imaging of the paracrine proangiogenic effects of progenitor cell therapy in limb ischemia. Circulation 2013, 127:710-719.

15. Kinnaird T, Stabile E, Burnett MS, Lee CW, Barr S, Fuchs S, Epstein SE: Marrow-derived stromal cells express genes encoding a broad spectrum of arteriogenic cytokines and promote in vitro and in vivo arteriogenesis through paracrine mechanisms. Circ Res 2004, 94:678-685.

16. Liew A, O'Brien T: Therapeutic potential for mesenchymal stem cell transplantation in critical limb ischemia. Stem Cell Res Ther 2012, 3:28.

17. Bianco P, Cao X, Frenette PS, Mao JJ, Robey PG, Simmons PJ, Wang C-Y: The meaning, the sense and the significance: translating the science of mesenchymal stem cells into medicine. Nat Med 2013, 19:35-42.

\section{$10.1186 /$ scrt351}

Cite this article as: Gremmels et al: Mesenchymal stromal cells for the treatment of critical limb ischemia: context and perspective. Stem Cell Research \& Therapy 2013, 4:140 